ARTICLE

\title{
Microporous metal-organic framework with dual functionalities for highly efficient removal of acetylene from ethylene/acetylene mixtures
}

\author{
Tong-Liang $\mathrm{Hu}^{1,2}$, Hailong Wang${ }^{2}$, Bin $\mathrm{Li}^{2}$, Rajamani Krishna ${ }^{3}, \mathrm{Hui} \mathrm{Wu}^{4}$, Wei Zhou ${ }^{4}$, Yunfeng Zhao ${ }^{5}$, \\ Yu Han ${ }^{5}$, Xue Wang ${ }^{6}$, Weidong Zhu ${ }^{6}$, Zizhu $\mathrm{Yao}^{7}$, Shengchang Xiang ${ }^{7}$ \& Banglin $\mathrm{Chen}^{2}$
}

The removal of acetylene from ethylene/acetylene mixtures containing $1 \%$ acetylene is a technologically very important, but highly challenging task. Current removal approaches include the partial hydrogenation over a noble metal catalyst and the solvent extraction of cracked olefins, both of which are cost and energy consumptive. Here we report a microporous metal-organic framework in which the suitable pore/cage spaces preferentially take up much more acetylene than ethylene while the functional amine groups on the pore/cage surfaces further enforce their interactions with acetylene molecules, leading to its superior performance for this separation. The single $X$-ray diffraction studies, temperature dependent gas sorption isotherms, simulated and experimental column breakthrough curves and molecular simulation studies collaboratively support the claim, underlying the potential of this material for the industrial usage of the removal of acetylene from ethylene/acetylene mixtures containing $1 \%$ acetylene at room temperature through the cost- and energy-efficient adsorption separation process.

\footnotetext{
${ }^{1}$ Department of Chemistry, TKL of Metal- and Molecule-Based Material Chemistry, Collaborative Innovation Center of Chemical Science and Engineering (Tianjin), Nankai University, Tianjin 300071, China. ${ }^{2}$ Department of Chemistry, University of Texas at San Antonio, One UTSA Circle, San Antonio, Texas 78249-0698, USA. ${ }^{3}$ Van 't Hoff Institute for Molecular Sciences, University of Amsterdam, Science Park 904, Amsterdam 1098 XH, The Netherlands. ${ }^{4}$ NIST Center for Neutron Research, Gaithersburg, Maryland 20899-6102, USA. ${ }^{5}$ Advanced Membranes and Porous Materials Center, Physical Sciences and Engineering Division, King Abdullah University of Science and Technology, Thuwal 23955-6900, Saudi Arabia. ${ }^{6}$ Key Laboratory of the Ministry of Education for Advanced Catalysis Materials, Institute of Physical Chemistry, Zhejiang Normal University, Jinhua 321004, China. ${ }^{7}$ College of Chemistry and Chemical Engineering, Fujian Provincial Key Laboratory of Polymer Materials, Fujian Normal University, Fuzhou 350007, China. Correspondence and requests for materials should be addressed to B.C. (email: Banglin.Chen@utsa.edu).
} 
E thylene is one of the most essential raw chemicals and widely used to produce polymers and other useful chemicals $^{1}$. During the production of ethylene through the cracking of ethane, propane and heavier hydrocarbons, a small amount of acetylene as an impurity of about $1 \%$ is also generated. It is imperative that acetylene in the ethylene feed should be reduced to an acceptable level because acetylene has a deleterious effect on end products of ethylene: acetylene can cause a catalyst poison during ethylene polymerization and thus significantly affect the quality of the resulting polyethylene. Furthermore, acetylene can form solid metal acetylides, which can block the fluid stream and lead to explosion ${ }^{2}$.

Extensive efforts have been pursued to remove acetylene from ethylene/acetylene mixtures 3,4 . In the petrochemical industry, current commercial approaches include partial hydrogenation of acetylene into ethylene over a noble metal catalyst such as a supported Pd catalyst and solvent extraction of cracked olefins using an organic solvent such as DMF and acetone. Both of which have some drawbacks: the former process suffers from the need of noble metal catalyst and the loss of olefins due to the over hydrogenation to paraffins, while the latter wastes a significant amount of solvents. Porous materials through selective adsorption separation of acetylene over ethylene might provide an alternative cost- and energy-efficient approach for this industrially very important while quite challenging task, though this has not been fully explored.

Among diverse porous materials, the emerging microporous metal-organic frameworks (MOFs) are of particular interest and are important for gas separation and thus removal of acetylene from ethylene/acetylene mixtures. This is because the pores within microporous MOFs can be straightforwardly and rationally tuned to enforce their size selective sieving effects while their pore surfaces can be readily functionalized to induce preferential interactions with specific gas molecules ${ }^{5-35}$. Although such a potential has been speculated, MOFs for the separation of $\mathrm{C}_{2} \mathrm{H}_{2} / \mathrm{C}_{2} \mathrm{H}_{4}$ have not been fully explored. We realized the first microporous MOF for this challenging separation in $2011^{36}$. We have been further able to tune the micropores through the interplay of metalloligands and organic linkers, and thus to optimize separation selectivities. Although the separation selectivities of these MOFs for the separation of $\mathrm{C}_{2} \mathrm{H}_{2} / \mathrm{C}_{2} \mathrm{H}_{4}$ are quite high because of their extraordinarily high sieving effects; their extremely narrow pores have also limited their acetylene uptake, which eventually affects their overall performance for separation of $\mathrm{C}_{2} \mathrm{H}_{2} / \mathrm{C}_{2} \mathrm{H}_{4}$, as clearly demonstrated in the simulated breakthrough curves ${ }^{37}$. Further development led to the discovery of MOF-74 series for $\mathrm{C}_{2} \mathrm{H}_{2} / \mathrm{C}_{2} \mathrm{H}_{4}$ separation in $2012^{38,39}$. This series of MOFs has high densities of open metal sites, which can significantly enforce their high acetylene uptake ${ }^{40,41}$, but their pores are too large to introduce sizesieving effects. Furthermore, the open metal sites have quite strong interactions with ethylene molecules, so MOF-74 series have systematically quite low selectivities for $\mathrm{C}_{2} \mathrm{H}_{2} / \mathrm{C}_{2} \mathrm{H}_{4}$ separation. The ideal MOFs for $\mathrm{C}_{2} \mathrm{H}_{2} / \mathrm{C}_{2} \mathrm{H}_{4}$ separation are those with high $\mathrm{C}_{2} \mathrm{H}_{2} / \mathrm{C}_{2} \mathrm{H}_{4}$ sieving effects but without sacrificing acetylene uptake. From the MOF structural point of view, these MOFs should still have comparatively narrow pores to enforce their high sieving effects, but these narrow pores should still take up moderate amount of acetylene molecules. Furthermore, some additional intercrossed cage spaces will be required to exclusively bind acetylene molecules and thus to maximize acetylene uptake. It should be theoretically feasible for us to design and realize MOFs to meet these criteria; however, in the reality, it is still a daunting challenge. Recently, there has been some progress on microporous MOFs for $\mathrm{C}_{2} \mathrm{H}_{2} / \mathrm{C}_{2} \mathrm{H}_{4}$ separation; however, their pore structures still cannot meet the above mentioned criteria and their separation performances are comparable to established ones ${ }^{42,43}$. Here we report a microporous $\mathrm{MOF}[\mathrm{Cu}(\mathrm{ATBDC})] \cdot \mathrm{G}$ (UTSA-100; $\mathrm{H}_{2} \mathrm{ATBDC}=5$-(5-Amino-1H-tetrazol-1-yl)-1,3-benzenedicarboxylic acid; $\mathrm{G}=$ guest molecules), based on our extensive research endeavours on microporous MOFs for $\mathrm{C}_{2} \mathrm{H}_{2} / \mathrm{C}_{2} \mathrm{H}_{4}$ separation, which can indeed meet those mentioned criteria. UTSA-100 is thus superior to other MOFs, exhibiting highly efficient removal of acetylene from ethylene/acetylene mixtures containing 1\% acetylene.

\section{Results}

Preparation and characterization of UTSA-100. The amino derivative of tetrazol-1,3-benzenedicarboxylic acid (5-(5-Amino$1 H$-tetrazol-1-yl)-1,3-benzenedicarboxylic acid, $\left.\mathrm{H}_{2} \mathrm{ATBDC}\right)$ was prepared based on alkaline decomposition of the tetrazole ring and heterocyclization of the resulting $N$-arylcyanamides on interaction with ammonium azide generated in situ. Reaction of $\mathrm{CuCl}_{2} \cdot 2 \mathrm{H}_{2} \mathrm{O}$ with $\mathrm{H}_{2} \mathrm{ATBDC}$ in the solvothermal condition at $353 \mathrm{~K}$ formed UTSA-100 as green block single crystals. It was formulated as $[\mathrm{Cu}(\mathrm{ATBDC})] \cdot \mathrm{G}$ (UTSA-100) by single-crystal $\mathrm{X}$-ray diffraction (SXRD) studies, and the phase purity of the bulk material was independently confirmed by powder X-ray diffraction (PXRD) (Supplementary Figs 4 and 5). The desolvated [Cu(ATBDC)] (UTSA-100a) for the adsorption studies was prepared from the acetone-exchanged samples followed by the activation under ultrahigh vacuum at room temperature $(296 \mathrm{~K})$ for one day, and then at $358 \mathrm{~K}$ for another 3 days. The PXRD profile of desolvated UTSA-100a indicates that it maintains the crystalline framework structure (Supplementary Fig. 5).

X-ray single-crystal structure reveals that UTSA-100 has a three-dimensional framework with rhombic open zigzag nanochannels with amino and tetrazole functionalized wall running in the $c$-direction (Fig. 1; Supplementary Table 1; Supplementary
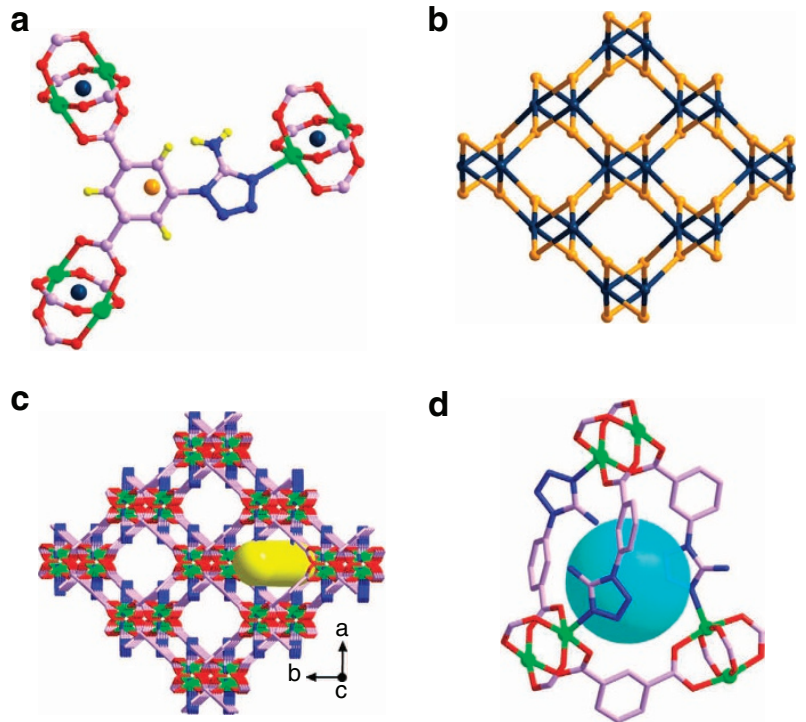

d

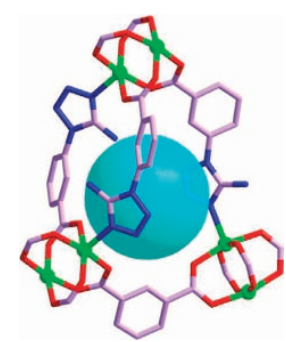

Figure 1 | X-ray crystal structure of UTSA-100. (a) The coordination environment of organic ligand $\mathrm{ATBDC}^{2-}$ and $\mathrm{Cu}(\mathrm{II})$, and dinuclear copper(II) unit as a 6-connected node (purple balls) and ATBDC ${ }^{2}$ - as a 3-connected node (orange ball). (b) The framework topology of apo-type $(3,6)$-connected network with Schläfli symbol $\left\{4 \cdot 6^{2}\right\}_{2}\left\{4^{2} \cdot 6^{9} \cdot 8^{4}\right\}$. (c) The $3 D$ structure viewed along the $c$ axis showing the $1 D$ rhombic channels of about $4.3 \AA$ in diameter. (d) The cage with a diameter of about $4.0 \AA$ between 1D channels with window openings of $3.3 \AA$. Solvent molecules were omitted for clarity. Colour scheme: $\mathrm{Cu}$, bright green; O, red; N, blue; C, orchid; and $\mathrm{H}$, yellow. 
Data 1). There are 6-connected binuclear $\mathrm{Cu}_{2}(\mathrm{COO})_{4}$ units, which are bridged by 3 -connected ATBDC ${ }^{2-}$ anions to form a (3,6)-connected apo-type network with Schläfli symbol $\left\{4.6^{2}\right\}_{2}\left\{4^{2} \cdot 6^{9} \cdot 8^{4}\right\}$ (Fig. 1b). The one-dimensional (1D) open zigzag channels with a diameter of about $4.3 \AA$ are filled with the disordered solvent molecules (DMF and $\mathrm{CH}_{3} \mathrm{OH}$ ), and there are small cages with the diameter of about $4.0 \AA$ between the $1 \mathrm{D}$ channels with window openings of $3.3 \AA$ (Fig. 1d). The calculated solvent accessible volume of UTSA-100a is $51.0 \%$, estimated using the PLATON program ${ }^{44}$.

Microporous nature of UTSA-100. To assess the permanent porosity, the acetone-exchanged UTSA-100 was further activated under high vacuum to obtain the desolvated UTSA-100a. The porosity of UTSA-100a was evaluated by $\mathrm{N}_{2}$-gas sorption at $77 \mathrm{~K}$. The type I isotherm shows a very sharp uptake at $P / P_{0}<0.1$, which clearly indicates its microporous nature (Supplementary Fig. 7a). The nitrogen physisorption of UTSA-100a reaches a plateau at around $P / P_{0}=0.1$, the saturation uptake is $257.6 \mathrm{~cm}^{3} \mathrm{~g}^{-1}$ and the corresponding specific pore volume is $0.399 \mathrm{~cm}^{3} \mathrm{~g}^{-1}$. The Langmuir (Brunauer, Emmett and Teller ) surface area based on the $\mathrm{N}_{2}$ adsorption isotherm at $77 \mathrm{~K}$ is 1,098 (970) $\mathrm{m}^{2} \mathrm{~g}^{-1}$ for UTSA-100a, within the pressure range of $0.05<P / P_{0}<0.3$ (Supplementary Fig. $7 \mathrm{~b}-\mathrm{d}$ ). The experimental determined Brunauer, Emmett and Teller surface of $970 \mathrm{~m}^{2} \mathrm{~g}^{-1}$ matches well with the simulated one $\left(913 \mathrm{~m}^{2} \mathrm{~g}^{-1}\right)$ from its crystal structure data.

Sorption of acetylene and ethylene within UTSA-100a. The unique pore structure encouraged us to examine the capacities of UTSA-100a for the selective separation of $\mathrm{C}_{2} \mathrm{H}_{2} / \mathrm{C}_{2} \mathrm{H}_{4}$. The lowpressure sorption isotherms of acetylene and ethylene were collected at 273 and $296 \mathrm{~K}$, respectively. At $296 \mathrm{~K}$ and $1 \mathrm{~atm}$, the acetylene and ethylene uptake amounts of UTSA-100a are 95.6 and $37.2 \mathrm{~cm}^{3} \mathrm{~g}^{-1}$, respectively (Fig. 2). This is really encouraging: the acetylene uptake of UTSA-100a is moderately high, while ethylene uptake is much lower. As shown in Table 1, the $\mathrm{C}_{2} \mathrm{H}_{2} /$ $\mathrm{C}_{2} \mathrm{H}_{4}$ uptake ratio of 2.57 in UTSA-100a is systematically higher than the examined MOFs except M'MOF-3a with very narrow pores, indicating its bright promise for the $\mathrm{C}_{2} \mathrm{H}_{2} / \mathrm{C}_{2} \mathrm{H}_{4}$ separation.

The measured pure component isotherm data for acetylene and ethylene on UTSA-100a were fitted with the dual-LangmuirFreundlich isotherm model. The fitted parameter values are presented in Supplementary Table 2. As illustration of the goodness of the fits, Supplementary Fig. 8 presents a comparison of component loadings for acetylene and ethylene at $296 \mathrm{~K}$ in UTSA-100a with the isotherm fits. The fits are excellent for both components over the entire pressure range.

The binding energy of acetylene is reflected in the isosteric heat of adsorption, $Q_{s t}$, defined as

$$
Q_{\mathrm{st}}=R T^{2}\left(\frac{\partial \ln p}{\partial T}\right)_{q}
$$

Supplementary Figure 10 presents a comparison of the heats of adsorption of acetylene in UTSA-100a with five other representative MOFs (M'MOF-3a, MgMOF-74, CoMOF-74, FeMOF-74 and NOTT-300); the calculations are based on the use of the Clausius-Clapeyron equation. We note that values of $Q_{s t}$ in UTSA-100a and M'MOF-3a are significantly lower than that of MOFs with coordinately unsaturated metal atoms FeMOF-74, CoMOF-74, and MgMOF-74. The value of $Q_{\mathrm{st}}$ in UTSA-100a is also lower than for NOTT-300. This implies that the regeneration energy requirement of UTSA-100a will be lower than that of FeMOF-74, CoMOF-74, MgMOF-74 and NOTT-300.
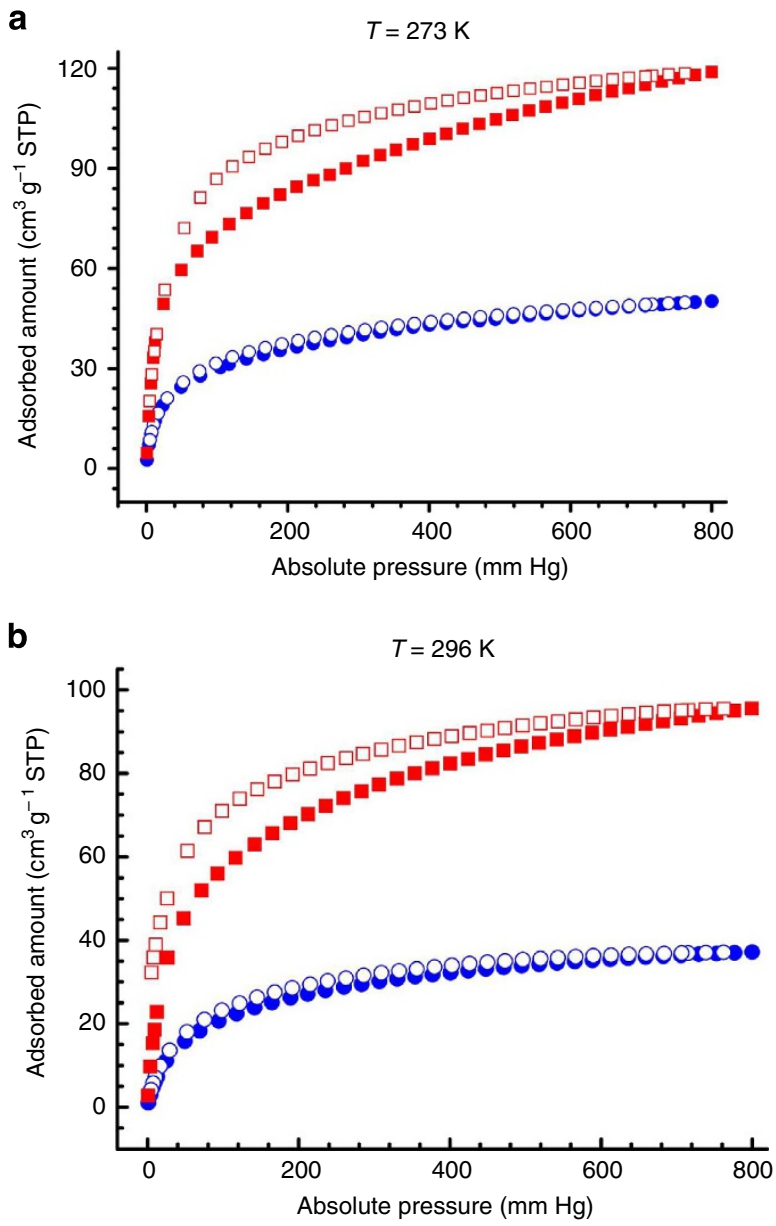

Figure 2 | Gas sorption isotherms on the activated UTSA-100a.

(a) Acetylene (red) and ethylene (blue) sorption at 273 K. (b) Acetylene (red) and ethylene (blue) sorption at $296 \mathrm{~K}$. Adsorption and desorption branches are shown with closed and open symbols, respectively.

IAST calculations of adsorption selectivities. Analysis of the pure component isotherms at $296 \mathrm{~K}$ via ideal adsorbed solution theory (IAST) ${ }^{45}$ was carried out to estimate the selectivity between acetylene and ethylene. We consider the separation of binary ethylene/acetylene mixtures containing $1 \%$, that is, 10,000 p.p.m., of acetylene, in the mixture; this composition is typical of industrial mixtures. Figure 3a presents the IAST calculations of the ethylene/acetylene adsorption selectivity, defined by

$$
S_{\mathrm{ads}}=\frac{q_{1} / q_{2}}{p_{1} / p_{2}} .
$$

The highest adsorption selectivity is with M'MOF-3a, and this is followed by UTSA-100a. MOFs with coordinately unsaturated metal atoms MgMOF-74, CoMOF-74 and FeMOF-74 have selectivities that are in the range of 1.6 to 2.2. NOTT-300 has selectivities in the range 1.8-2.1.

In the paper by Yang et al. ${ }^{42}$, the ethylene/acetylene mixtures for NOTT-300 are compared with FeMOF-74 for varying mole fraction of acetylene in the gas phase, keeping the total gas phase pressure constant at $100 \mathrm{kPa}$. It must be remarked that in industrial practice, the compositions of acetylene in the gas phase are $<1 \%$. Also, acetylene is selectively adsorbed from ethylene/ acetylene mixtures, and the bulk gas phase compositions will vary from $1 \%$ at the inlet to the desired 40 p.p.m. limit at the outlet of the fixed-bed absorber. Nevertheless, in order to compare our 
Table 1 | Adsorption data.

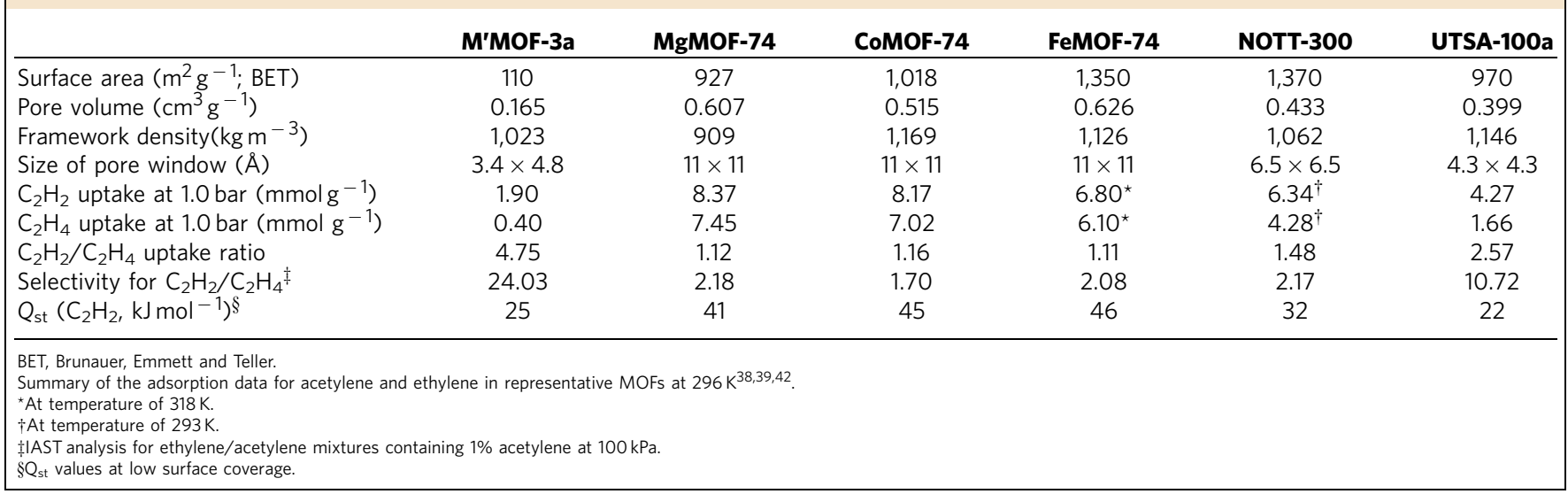
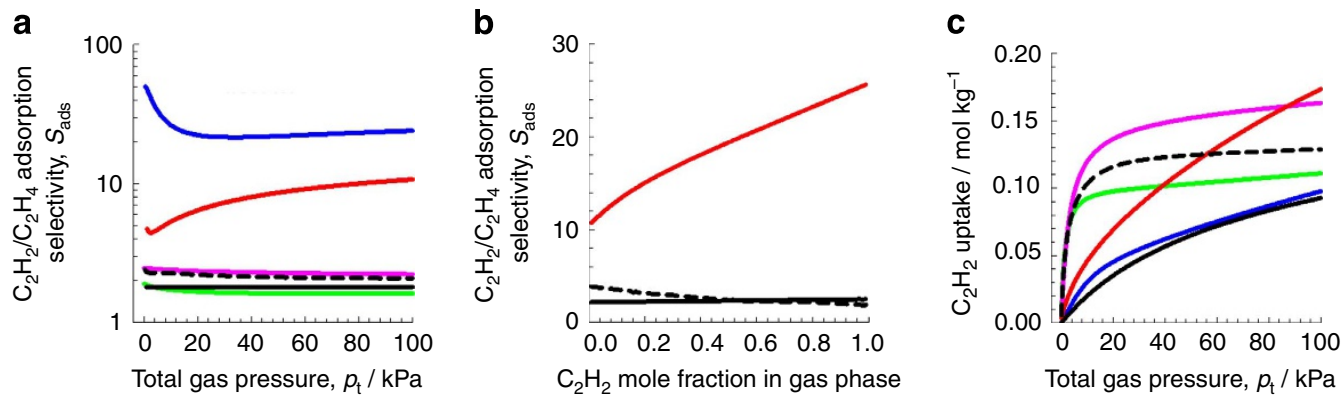

Figure 3 | IAST calculations for binary $\mathbf{C}_{\mathbf{2}} \mathbf{H}_{\mathbf{2}} / \mathbf{C}_{\mathbf{2}} \mathbf{H}_{\mathbf{4}}$ mixture on the MOFs. (a) $\mathrm{C}_{2} \mathrm{H}_{2} / \mathrm{C}_{2} \mathrm{H}_{4}$ adsorption selectivity, and (c) uptake capacity of $\mathrm{C}_{2} \mathrm{H}_{2}$ for adsorption from $\mathrm{C}_{2} \mathrm{H}_{2} / \mathrm{C}_{2} \mathrm{H}_{4}$ mixture containing $1 \% \mathrm{C}_{2} \mathrm{H}_{2}$. The total bulk gas phase is at $296 \mathrm{~K}$ and $100 \mathrm{kPa}$. The partial pressures of $\mathrm{C}_{2} \mathrm{H}_{2}$, and $\mathrm{C}_{2} \mathrm{H}_{4}$ are, respectively, $p 1=1 \mathrm{kPa}, p 2=99 \mathrm{kPa}$. (b) IAST calculations of the $\mathrm{C}_{2} \mathrm{H}_{2} / \mathrm{C}_{2} \mathrm{H}_{4}$ adsorption selectivity for FeMOF-74, NOTT-300, and UTSA-100a as a function of the mole fraction of $\mathrm{C}_{2} \mathrm{H}_{2}$ in the gas phase. The total gas pressure is constant at $100 \mathrm{kPa}$. The data for FeMOF-74 is at the temperature of $318 \mathrm{~K}$; this is the lowest temperature used in the isotherm measurements of Bloch et al. ${ }^{38}$. The data for NOTT-300 is at 293 K. M'MOF-3a (blue), MgMOF-74 (pink), CoMOF-74 (green), FeMOF-74 (black dash), NOTT-300 (black) and UTSA-100a (red).

IAST calculation methodology with those of Yang et al., we carried out similar comparison, also including UTSA-100a; the results are shown in Fig. 3b. Our IAST selectivity calculations for NOTT-300 and FeMOF-74 agree reasonably well with those of Yang et al., We note that UTSA-100a has significantly higher selectivity than both NOTT-300 and FeMOF-74.

As shown in Fig. 3c, the gravimetric uptake capacity of acetylene in UTSA-100a for adsorption from $\mathrm{C}_{2} \mathrm{H}_{2} / \mathrm{C}_{2} \mathrm{H}_{4}$ mixtures containing $1 \% \mathrm{C}_{2} \mathrm{H}_{2}$ is compared with other five MOFs (M'MOF-3a, MgMOF-74, CoMOF-74, FeMOF-74 and NOTT300 ). At a total gas phase pressure of $100 \mathrm{kPa}$, the hierarchy of uptake capacities for acetylene is UTSA-100a $>$ MgMOF$74>$ FeMOF-74 $>$ CoMOF-74 $>$ M'MOF-3a $\approx$ NOTT-300.

Ethylene/acetylene breakthrough simulations and experiments. We carried out breakthrough simulations for $\mathrm{C}_{2} \mathrm{H}_{2} / \mathrm{C}_{2} \mathrm{H}_{4}(1: 99$, v/v) mixture, whose composition is typical of industrial mixtures, in a fixed-bed to demonstrate the feasibility of purification of ethylene in a Pressure Swing Adsorption operation. The transient breakthrough simulations show the concentrations of $\mathrm{C}_{2} \mathrm{H}_{2} / \mathrm{C}_{2} \mathrm{H}_{4}$ exiting the adsorber packed with UTSA-100a as a function of the dimensionless time, $\tau$ (Fig. 4a). Analogous breakthrough simulations were performed for M'MOF-3a, MgMOF-74, CoMOF-74, FeMOF-74 and NOTT-300. On the basis of the gas phase concentrations, we can calculate the impurity level of acetylene in the gas mixture exiting the fixed-bed packed with six different MOFs. Figure $4 \mathrm{~b}$ shows the p.p.m. $\mathrm{C}_{2} \mathrm{H}_{2}$ in the outlet gas mixture exiting an adsorber packed with M'MOF-3a, MgMOF-74, CoMOF-74, FeMOF-74, NOTT-300 and UTSA-100a. At a certain time, $\tau_{\text {break, }}$ the impurity level will exceed the desired purity level of 40 p.p.m. (indicated by the dashed line), that corresponds to the purity requirement of the feed to the polymerization reactor. The adsorption cycle needs to be terminated at that time $\tau_{\text {break }}$ and the regeneration process needs to be initiated. From a material balance on the adsorber, the amount of acetylene captured during the time interval $0-\tau_{\text {break }}$ can be determined. The amount of acetylene captured in UTSA-100a during the time $0-\tau_{\text {break }}$ is $137.6 \mathrm{mmoll}^{-1}$, which is the best one among the compared six MOFs and approximately twice that of NOTT-300 (Supplementary Table 5). A plot of the amount of acetylene captured plotted as a function of the time interval $\tau_{\text {break }}$ is presented in Fig. 4c. The hierarchy of acetylene capture capacities is UTSA-100a $>$ MgMOF-74 $>$ FeMOF$74>$ CoMOF-74 $>$ M'MOF-3a $>$ NOTT-300. The significantly superior performance of UTSA-100a is attributable to a combination of high adsorption selectivity and high uptake capacity. M'MOF-3a has the highest selectivity but the lowest uptake capacity; this results in poorer performance in the industrial fixed-bed adsorber. It needs to be pointed out that the separations in fixedbed adsorbers are determined by a combination of adsorption selectivity and uptake capacity. Transient breakthrough simulations can provide us some guidance on the potentials of materials for 
a
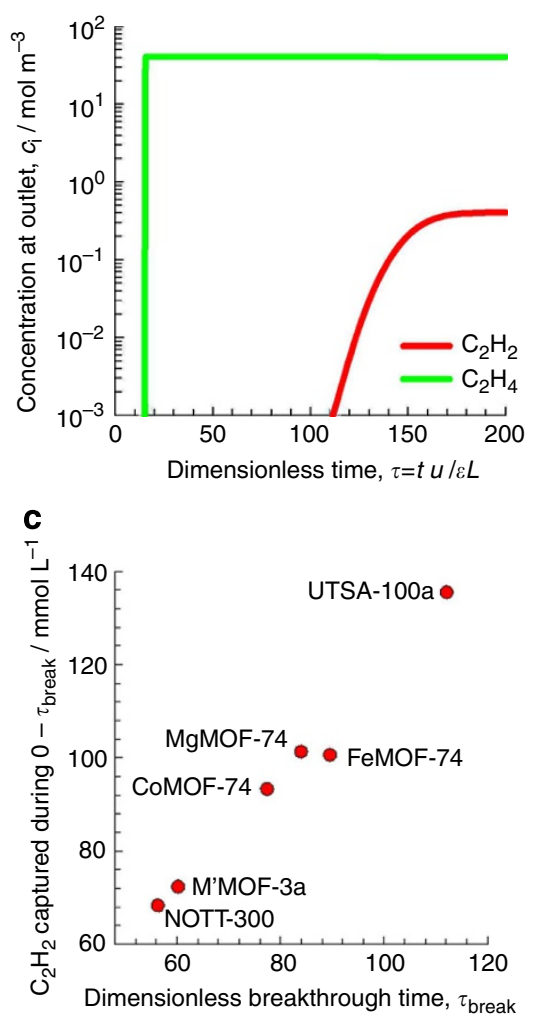

b

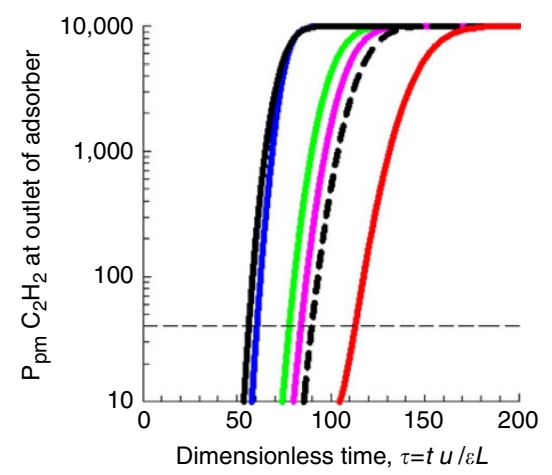

d

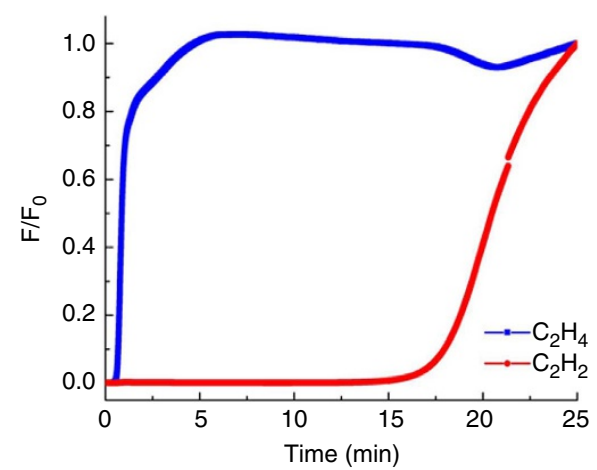

Figure 4 | Simulative and experimental column breakthrough experiments. (a) Transient breakthrough curve of $\mathrm{C}_{2} \mathrm{H}_{2} / \mathrm{C}_{2} \mathrm{H}_{4}$ mixture containing $1 \% \mathrm{C}_{2} \mathrm{H}_{2}$ in an adsorber bed packed with UTSA-100a. The partial pressures of $\mathrm{C}_{2} \mathrm{H}_{2}$, and $\mathrm{C}_{2} \mathrm{H}_{4}$ in the inlet feed gas mixture are, respectively, $p_{1}=1 \mathrm{kPa}, p_{2}=99 \mathrm{kPa}$. For the breakthrough simulations, the following parameter values were used, $L=0.12 \mathrm{~m} ; \varepsilon=0.75 ; u=0.00225 \mathrm{~m} \mathrm{~s}^{-1}$. (b) $\mathrm{Ppm} \mathrm{C}_{2} \mathrm{H}_{2}$ in the outlet gas of an adsorber bed packed with UTSA-100a and various MOFs. M'MOF-3a (blue), MgMOF-74 (pink), CoMOF-74 (green), FeMOF-74 (black dash), NOTT-300 (black), and UTSA-100a (red). (c) Plot of $\mathrm{C}_{2} \mathrm{H}_{2}$ captured per $\mathrm{L}$ of adsorbent ( $<40$ ppm $\mathrm{C}_{2} \mathrm{H}_{2}$ in outlet gas), during the time interval 0- $\tau_{\text {break, }}$ plotted as a function of the time interval $\tau_{\text {break. }}$ (d) Experimental column breakthrough curve for $\mathrm{C}_{2} \mathrm{H}_{2} / \mathrm{C}_{2} \mathrm{H}_{4}$ mixed gas containing $1 \% \mathrm{C}_{2} \mathrm{H}_{2}$ over UTSA-100a. The experiment temperatures are $296 \mathrm{~K}$ except FeMOF-74 (318 K) and NOTT-300 (293 K).

their real industrial applications. They can also offer more information than IAST calculations, and help us to make a clear comparison with other MOFs.

To evaluate the performance of UTSA-100a in the actual adsorption-based separation and purification processes, breakthrough experiments were performed in which an $\mathrm{C}_{2} \mathrm{H}_{2} / \mathrm{C}_{2} \mathrm{H}_{4}$ $(1: 99, \mathrm{v} / \mathrm{v})$ mixture was flowed over a packed bed of UTSA-100a solid with a total flow of $2 \mathrm{ml} \mathrm{min}^{-1}$ at $296 \mathrm{~K}$. As shown in Fig. $4 \mathrm{~d}$, the separation of $\mathrm{C}_{2} \mathrm{H}_{2} / \mathrm{C}_{2} \mathrm{H}_{4}(1: 99, \mathrm{v} / \mathrm{v})$ mixture through the column packed bed of UTSA-100a solid can be efficiently achieved. To the best of our knowledge, this is the first example of porous materials whose separation for $\mathrm{C}_{2} \mathrm{H}_{2} / \mathrm{C}_{2} \mathrm{H}_{4}(1: 99$, v/v) has been clearly established by experimental breakthrough, enabling UTSA-100a to be a potential high-performance material for real industrial ethylene purification application.

Pore structure analysis and first-principles calculations. To correlate the excellent $\mathrm{C}_{2} \mathrm{H}_{2} / \mathrm{C}_{2} \mathrm{H}_{4}$ separation performance of UTSA-100a to its structure, we carried out more detailed pore structure analysis. As mentioned earlier, the overall MOF pore size is centred at $4.3 \AA$, with rather narrow distribution (Fig. 5c). Gas adsorption and diffusion would thus take place predominantly within individual channel pores, with interchannel diffusion limited by the narrow window opening between adjacent channels and the size of gas molecules. The pore size variation along the pore channel (in crystallography $c$ axis direction) is shown in
Fig. 5d. Clearly, the pore limiting size (for the access of guest gas molecule into the MOF crystal) is $3.96 \AA$, while the largest cavity within the channel is $4.6 \AA$ in diameter. Note that the empirical kinetic diameters of $\mathrm{C}_{2} \mathrm{H}_{2} / \mathrm{C}_{2} \mathrm{H}_{4}$ are $\sim 3.3 / 4.2 \AA$ $\left(3.32 \times 3.34 \times 5.70 \AA^{3}\right.$ for $\mathrm{C}_{2} \mathrm{H}_{2}$ versus $3.28 \times 4.18 \times 4.84 \AA^{3}$ for $\mathrm{C}_{2} \mathrm{H}_{4}$ ), respectively ${ }^{46-49}$. For ethylene, its kinetic diameter is slightly larger than the channel pore opening of UTSA-100a, and much larger than the interchannel window size. These two factors may significantly hinder/block the ethylene adsorption and diffusion in the MOF structure, leading to the much lower ethylene uptakes than acetylene ones.

To further understand the acetylene adsorption in UTSA-100a, we performed detailed computational investigations (Supplementary Methods). We first optimized the bare UTSA$100 \mathrm{a}$ structure by first-principles DFT-D (dispersion-corrected density-functional theory) calculations, where van der Waals interactions were corrected by empirical $r^{-6}$ terms ${ }^{50}$. The optimized structure is fairly close to the experimentally determined structure. We then introduced acetylene molecules to various locations of the channel pore, and further optimized the 'UTSA-100a $+\mathrm{C}_{2} \mathrm{H}_{2}$ ' structures using DFT-D. Interestingly, the guest acetylene molecules all get relaxed to a particular adsorption sites. In Fig. 5b, we plot this preferred acetylene adsorption location. The acetylene sits right at the small cage connecting two adjacent channel pores. The relatively strong binding clearly comes from multiple-point interactions of the molecule with framework (particularly, the metal center $\mathrm{O}$, the linker tetrazole rings and - 


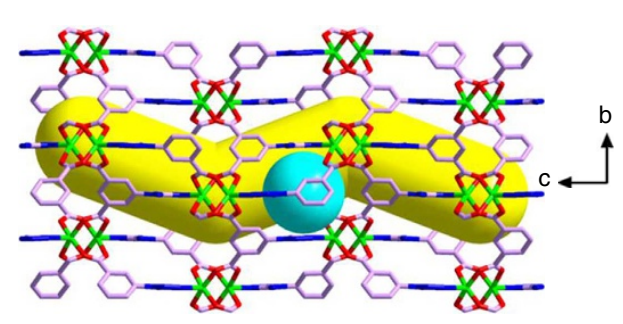

b

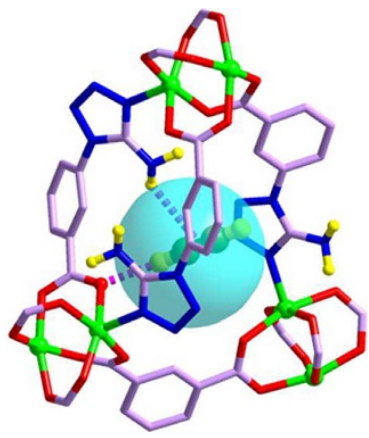

c

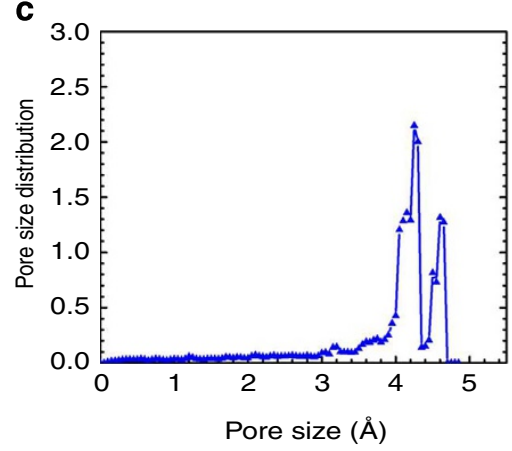

d

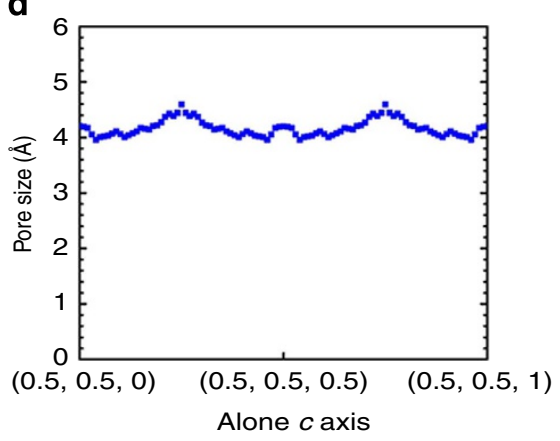

Figure 5 | The pore structure of UTSA-100 and the $\mathbf{C}_{\mathbf{2}} \mathbf{H}_{\mathbf{2}}$ binding site. (a) The pore structure showing the zigzag channels along the $c$ axis and the cage with a diameter of about $4.0 \AA$ in the pore wall with window openings of $3.3 \AA$. (b) The acetylene sits right at the small cage connecting two adjacent channel pores. (multiple-point interactions of the acetylene molecule with framework: $d\left[O\left(-\mathrm{CO}_{2}\right) \cdots H\left(\mathrm{C}_{2} \mathrm{H}_{2}\right)\right]=2.252 \AA, d\left[H\left(-\mathrm{NH}_{2}\right) \cdots\left(\mathrm{C}_{2} \mathrm{H}_{2}\right)\right]=$ $2.856 \AA$ ). (c) Pore size distribution (PSD) of UTSA-100a. PSD was calculated using the well-known method by Gubbins et al. ${ }^{58}$. The van der Waals diameters of the framework atoms were adopted from the Cambridge Crystallographic Center. (d) Pore size variation along the pore channel (in $c$ axis direction), within the crystal unit cell of UTSA-100a. Colour scheme: $\mathrm{Cu}$, bright green; $\mathrm{O}$, red; N, blue; $\mathrm{C}$, orchid (green in acetylene); and $\mathrm{H}$, yellow.

$\mathrm{NH}_{2}$ groups, Fig. 5b). These binding sites are typically classified as specific and/or strong sites for gas recognitions ${ }^{29}$. The interactions between the metal center $\mathrm{O}$ with $\mathrm{C}_{2} \mathrm{H}_{2}$ can be assigned as hydrogen bonding interactions. Given the fact that aromatic $-\mathrm{NH}_{2}$ has weak basicity, while $\mathrm{C}_{2} \mathrm{H}_{2}$ has weak acidity $(\mathrm{pKa}=25)^{51}$, there might exist weak acid-base interactions between $-\mathrm{NH}_{2}$ groups and $\mathrm{C}_{2} \mathrm{H}_{2}$ molecules. Because $\mathrm{C}_{2} \mathrm{H}_{2}$ is more acidic than $\mathrm{C}_{2} \mathrm{H}_{4}$ $(\mathrm{pKa}=44)^{51}$, the $-\mathrm{NH}_{2}$ groups have stronger interactions with $\mathrm{C}_{2} \mathrm{H}_{2}$ than $\mathrm{C}_{2} \mathrm{H}_{4}$, which enforces the selective binding of UTSA100a for $\mathrm{C}_{2} \mathrm{H}_{2}$ than $\mathrm{C}_{2} \mathrm{H}_{4}$ as well. It is suggested that the relatively narrower pore size allows and reinforces one acetylene molecule to interact mutually with $-\mathrm{NH}_{2}$ group and one metal center $\mathrm{O}$ atom. We note that the adsorbed acetylene is slightly distorted, with an induced dipole moment. The $\mathrm{H}-\mathrm{C}-\mathrm{C}$ bond angle of acetylene is $178.8^{\circ}$, comparable to that of acetylene adsorbed on the open- $\mathrm{Cu}$ site in HKUST-1 $\left(\sim 178^{\circ}\right)^{40}$. The static acetylene binding energy, derived from the DFT-D calculation, is $\sim 31.3 \mathrm{~kJ} \mathrm{~mol}^{-1}$. This value (without considering the thermal correction, which is typically a few $\mathrm{kJmol}^{-1}$ ) is somewhat larger than the experimental $Q_{s t}$ value but still reasonable, considering the accuracy limitation of the DFT-D approach.

\section{Discussion}

Removal of acetylene from ethylene/acetylene mixtures containing $1 \%$ acetylene is a very important but challenging industrial separation task. It has been speculated that adsorption-based porous materials could be the good alternative for the highly efficient removal of acetylene from ethylene steam, but have not been fully fulfilled. To evaluate a porous material for acetylene removal from ethylene, adsorption selectivity and saturation uptake capacity have been deemed as two most important criteria, and high values for both of them are needed to achieve high effectiveness and high efficiency for acetylene removal. However, which factor plays the dominant role depends on the composition of gas mixtures. For the ethylene/acetylene mixtures containing $1 \%$ acetylene, adsorption selectivity will be enough more important than acetylene adsorption capacity. Comparing with other five well-known MOFs (M'MOF-3a, MgMOF-74, CoMOF74, FeMOF-74 and NOTT-300), the significantly superior performance of UTSA-100a in removing acetylene from ethylene/acetylene mixtures containing $1 \%$ acetylene is attributable to the collaboration of high adsorption selectivity and high uptake capacity at ambient conditions. From the structure point of view, UTSA-100a has suitable pores and opening windows to enforce its high sieving effects and thus high adsorption selectivities, while the suitable cages and immobilized functional sites such $\mathrm{NH}_{2}$ further maximize the acetylene uptakes. It is speculated that weak acid-base interactions between $-\mathrm{NH}_{2}$ and $\mathrm{C}_{2} \mathrm{H}_{2}$ molecules also play the important roles for the preferential binding of UTSA-100a with $\mathrm{C}_{2} \mathrm{H}_{2}$ over $\mathrm{C}_{2} \mathrm{H}_{4}$. Incorporation of stronger basic sites such as alkaneamines into porous MOFs might significantly differentiate their interactions with $\mathrm{C}_{2} \mathrm{H}_{2}$ over $\mathrm{C}_{2} \mathrm{H}_{4}$, leading to even more efficient MOF materials for $\mathrm{C}_{2} \mathrm{H}_{2} / \mathrm{C}_{2} \mathrm{H}_{4}$ separations in the future.

It is to be noted that our comparisons of different MOFs are for ethylene/acetylene mixtures containing $1 \%$ acetylene that is representative of compositions encountered in industry. If we were to compare the performance of UTSA-100a, NOTT-300 and FeMOF-74 for 50/50 ethylene/acetylene mixtures, the conclusions are different because in this case, capacity considerations would be very important. Supplementary Figure 11 presents a comparison of breakthroughs for UTSA-100a, NOTT-300, and FeMOF-74 for 50/50 ethylene/acetylene mixtures. In this case the 
performance of NOTT-300 and UTSA-100a are nearly the same. The best separations are achieved with FeMOF-74 that has the highest capacity to adsorb acetylene. These results also underscore the need for a proper evaluation of MOFs using transient breakthroughs. Comparisons based pure on selectivities may lead to wrong conclusions.

In conclusion, we have prepared a microporous MOF (UTSA100) for highly efficient removal of acetylene from ethylene/ acetylene mixtures containing 1\% acetylene. Experimental and computational simulation results demonstrate the high efficiency of UTSA-100a in the removal of acetylene from ethylene/ acetylene mixtures containing $1 \%$ acetylene, which is a very important but challenging industrial separation task. The results of this research have important significance on the practical design and preparation of porous materials for light hydrocarbon separations. It will also provide some guidance on the design and synthesis of microporous MOFs for other gas separations.

\begin{abstract}
Methods
Materials and measurements. Commercially available reagents were purchased in high purity and used without further purification. 5-(5-amino- $1 H$-tetrazol-1-yl)1,3-benzenedicarboxylic acid $\left(\mathrm{H}_{2} \mathrm{ATBDC}\right)$ was synthesized according to the literature method ${ }^{52}$ (Supplementary Fig. 1). ${ }^{1} \mathrm{H}$ NMR and ${ }^{13} \mathrm{C}$ NMR spectra were obtained using a Varian INOVA $500 \mathrm{MHz}$ spectrometer at room temperature. FTIR spectra were performed on a Bruker Vector 22 spectrometer at room temperature. Thermal gravimetric analysis (TGA) was performed under a nitrogen atmosphere with a heating rate of $3^{\circ} \mathrm{C} \mathrm{min}^{-1}$ using a Shimadzu TGA-50 thermogravimetric analyzer. PXRD patterns were measured by a Rigaku Ultima IV diffractometer operated at $40 \mathrm{kV}$ and $44 \mathrm{~mA}$ with a scan rate of $1.0 \mathrm{deg} \mathrm{min}{ }^{-1}$.
\end{abstract}

Synthesis of 5-(1H-tetrazol-1-yl)-1,3-benzenedicarboxylic acid. Glacial acetic acid $(10.0 \mathrm{ml})$ was added with stirring to a suspension of 5 -aminoisophthalic acid $(4.54 \mathrm{~g}, 0.025 \mathrm{~mol})$, and sodium azide $(1.79 \mathrm{~g}, 0.0275 \mathrm{~mol})$ in triethyl orthoformate $(14.2 \mathrm{ml}, 0.075 \mathrm{~mol})$, and the mixture was stirred at $80-90^{\circ} \mathrm{C}$ for $6 \mathrm{~h}$. The reaction mixture was cooled, and concentrated hydrochloric acid $(4.2 \mathrm{ml}, 0.05 \mathrm{~mol})$ and water $(12.5 \mathrm{ml})$ were added. The precipitated solid was separated by filtration, washed with water and dried. The obtained raw product was recrystallized from DMF. Yield: $82 \%\left(4.79\right.$ g). ${ }^{1} \mathrm{H}$ NMR (500 MHz, $d^{6}$-DMSO, p.p.m.): $\delta 13.78$ (s, $2 \mathrm{H},-$ $\left.\mathrm{CO}_{2} \mathrm{H}\right), 10.33\left(\mathrm{~s}, 1 \mathrm{H},-\mathrm{N}_{4} \mathrm{CH}\right), 8.65\left(\mathrm{~s}, 2 \mathrm{H},-\mathrm{C}_{6} \mathrm{H}_{3}\right), 8.55\left(\mathrm{~s}, 1 \mathrm{H},-\mathrm{C}_{6} \mathrm{H}_{3}\right)$

\section{Synthesis of 5-(cyanoamino)-1,3-benzenedicarboxylic acid. DMSO $(20.0 \mathrm{ml})$} was added dropwise with constant stirring to a suspension of 5-(1H-tetrazol-1-yl)1,3-benzenedicarboxylic acid $(4.68 \mathrm{~g}, 0.02 \mathrm{~mol})$ in $22 \%$ aqueous $\mathrm{KOH}$ solution $(12.0 \mathrm{ml})$. Gas evolution was observed, accompanied by self-heating of the reaction mixture. Stirring of the reaction mixture was continued for 2 days. The mixture was then diluted to $160 \mathrm{ml}$ with water, acidified with concentrated hydrochloric acid to pH 3-4 and stored at $5-10{ }^{\circ} \mathrm{C}$ until precipitation of solid. The obtained product was filtered off and dried in vacuum. Another portion of product was reprecipitated from the filtrate through salting out method using sodium salt. Yield: $93 \%(3.83 \mathrm{~g}) .{ }^{1} \mathrm{H}$ NMR (500 MHz, d ${ }^{6}$-DMSO, p.p.m.): $\delta=7.67\left(\mathrm{~s}, 1 \mathrm{H},-\mathrm{C}_{6} \mathrm{H}_{3}\right), 7.40\left(\mathrm{~s}, 2 \mathrm{H},-\mathrm{C}_{6} \mathrm{H}_{3}\right)$.

\section{Synthesis of 5-(5-amino-1H-tetrazol-1-yl)-1,3-benzenedicarboxylic acid. A} suspension of 5-(cyanoamino)-1,3-benzenedicarboxylic acid (2.06 g, $0.01 \mathrm{~mol})$, sodium azide $(0.98 \mathrm{~g}, 0.015 \mathrm{~mol})$ and ammonium chloride $(1.07 \mathrm{~g}, 0.02 \mathrm{~mol})$ in DMF $(25 \mathrm{ml})$ was stirred at $70-80^{\circ} \mathrm{C}$ for $6 \mathrm{~h}$, after which water $(100 \mathrm{ml})$ was added to the reaction mixture. The white solid was precipitated through salting out method using sodium salt. The obtained product was filtered off, and dried in vacuum. Yield: $82 \%(2.04 \mathrm{~g}) .{ }^{1} \mathrm{H}$ NMR $\left(500 \mathrm{MHz}, \mathrm{D}_{2} \mathrm{O}\right.$, p.p.m.): $\delta=8.47$ $\left(\mathrm{s}, 1 \mathrm{H},-\mathrm{C}_{6} \mathrm{H}_{3}\right), 8.14\left(\mathrm{~s}, 2 \mathrm{H},-\mathrm{C}_{6} \mathrm{H}_{3}\right)$ (Supplementary Fig. 2$) .{ }^{3} \mathrm{C}$ NMR $\left(\mathrm{D}_{2} \mathrm{O}\right.$, p.p.m.): $\delta=173.00,138.49,132.35,130.43,126.94$ (Supplementary Fig. 3).

Synthesis of UTSA-100. A mixture of $\mathrm{CuCl}_{2} \cdot 2 \mathrm{H}_{2} \mathrm{O}(34 \mathrm{mg}, 0.2 \mathrm{mmol})$ and the organic linker $\mathrm{H}_{2} \mathrm{ATBDC}(50 \mathrm{mg}, 0.2 \mathrm{mmol})$ was dispersed into an $8 \mathrm{ml}$ mixed solvent $(\mathrm{DMF} / \mathrm{MeOH}, 5 / 3, \mathrm{v} / \mathrm{v})$ in a screw-capped vial $(20 \mathrm{ml})$. And five drops of $\mathrm{HBF}_{4}(48 \% \mathrm{w} / \mathrm{w}$ aqueous solution) were added. The suspension was sonicated until homogenous. The vial was capped and heated in an oven at $80^{\circ} \mathrm{C}$ for $24 \mathrm{~h}$. Green block crystals were obtained by filtration and washed with DMF several times to afford UTSA-100. IR (neat, $\mathrm{cm}^{-1}$ ): $1,739 \mathrm{w} ; 1,630 \mathrm{~s} ; 1,596 \mathrm{~m} ; 1,490 \mathrm{w} ; 1,457 \mathrm{~m}$; $1,377 \mathrm{~s} ; 1,255 \mathrm{~m} ; 1,128 \mathrm{w} ; 1,097 \mathrm{~m} ; 1,062 \mathrm{w} ; 908 \mathrm{~m} ; 780 \mathrm{~m} ; 725 \mathrm{~s} ; 677 \mathrm{~m} ; 661 \mathrm{~m}$.

Gas sorption studies. A Micromeritics ASAP 2020 surface area analyzer was used to measure gas adsorption isotherms. To remove all the guest solvents in the framework, the fresh sample of UTSA-100 was guest exchanged with dry acetone at least 10 times, filtered and degassed at room temperature $(296 \mathrm{~K})$ for one day, and then at $358 \mathrm{~K}$ for another 3 days until the outgas rate was $5 \mu \mathrm{mHg} \mathrm{min}^{-1}$ before measurements. A sample of activated UTSA-100a (100-150 mg) was used for the sorption measurement and was maintained at $77 \mathrm{~K}$ with liquid nitrogen, at $273 \mathrm{~K}$ with an ice-water bath. As the center-controlled air conditioner was set up at $23^{\circ} \mathrm{C}$, a water bath was used for adsorption isotherms at $296 \mathrm{~K}$.

Fitting of pure component isotherms. Experimental data on pure component isotherms for acetylene and ethylene in UTSA-100a were measured at temperatures of 273 and $296 \mathrm{~K}$. The pure component isotherm data for acetylene and ethylene were fitted with the dual-Langmuir-Freundlich isotherm model

$$
q=q_{A, \text { sat }} \frac{b_{A} p^{v_{A}}}{1+b_{A} p^{v_{A}}}+q_{B, \text { sat }} \frac{b_{B} p^{v_{B}}}{1+b_{B} p^{v_{B}}}
$$

with $T$-dependent parameters $b_{\mathrm{A}}$ and $b_{\mathrm{B}}$

$$
b_{A}=b_{A 0} \exp \left(\frac{E_{A}}{R T}\right) ; \quad b_{B}=b_{B 0} \exp \left(\frac{E_{B}}{R T}\right)
$$

The fitted parameter values are presented in Supplementary Table 2.

For FeMOF-74, the dual-site Langmuir-Freundlich parameters are from Bloch et al. ${ }^{38}$; for convenience, the parameters are summarized in Supplementary Table 3. For NOTT-300, the isotherm data at $293 \mathrm{~K}$ were fitted with a single-site Langmuir isotherm model; the fit parameters are specified in Supplementary Table 4. Supplementary Figure 9 presents a comparison of component loadings for acetylene and ethylene at $293 \mathrm{~K}$ in NOTT-300 with 1-site Langmuir isotherm fits. The Langmuir fits are of good accuracy. For all other MOFs, the isotherm data are from He et al. ${ }^{39}$.

Transient breakthrough of ethylene/acetylene mixtures in fixed-bed adsorbers. The performance of industrial fixed-bed adsorbers is dictated by a combination of adsorption selectivity and uptake capacity. For a proper comparison of various MOFs, we perform transient breakthrough simulations using the simulation methodology described in the literature ${ }^{53-55}$. For the breakthrough simulations, the following parameter values were used: framework density, $\rho\left(1,146 \mathrm{~kg} \mathrm{~m}^{-3}\right)$; length of packed bed, $L(0.12 \mathrm{~m})$; voidage of packed bed, $\varepsilon(0.75)$; superficial gas velocity at inlet, $u\left(0.00225 \mathrm{~m} \mathrm{~s}^{-1}\right)$. For breakthrough simulations with NOTT-300, we use calculated the framework density from the crystal structure information provided in the paper of Yang et al. ${ }^{42}$; the resultant value is $\rho\left(1,062 \mathrm{~kg} \mathrm{~m}^{-3}\right)$. The framework densities for all other MOFs are available in the papers by Bloch et al. ${ }^{38}$ and He et al. ${ }^{39}$. The transient breakthrough simulation results are presented in terms of a dimensionless time, $\tau$, defined by dividing the actual time, $t$, by the characteristic time, $\frac{L \varepsilon}{u}$.

Column breakthrough tests. The breakthrough separation experiments were conducted on a home-made apparatus (Supplementary Fig. 12) with a set-up similar to what was described in Yaghi's paper ${ }^{56}$. In a typical experiment, $1.00 \mathrm{~g}$ of UTSA-100a powders were thoroughly ground and packed into a quartz column $(5.8 \mathrm{~mm}$ inner diameter $\times 150 \mathrm{~mm})$ with quartz wool filling the void space. The sample was in situ activated under vacuum $\left(6.5 \times 10^{-4} \mathrm{~Pa}\right)$ at $353 \mathrm{~K}$ to remove adsorbed molecules and make the active sites accessible. The sample was then purged with He flow $\left(2.0 \mathrm{ml} \mathrm{min}^{-1}\right)$ for $1 \mathrm{~h}$ while the temperature of the column was decreased to $296 \mathrm{~K}$. The mix gas $\left(\mathrm{C}_{2} \mathrm{H}_{2}: \mathrm{C}_{2} \mathrm{H}_{4}=1\right.$ : 99 by volume) flow was then introduced at $2.0 \mathrm{ml} \mathrm{min}^{-1}$. Effluent from the column was monitored using a mass spectrometer.

Caution: Because of its wide flammability limits and a potential for explosive decomposition ${ }^{57}$, acetylene should be handled with care.

\section{References}

1. Sundaram, K. M., Shreehan, M. M. \& Olszewski, E. F. Kirk-Othmer Encyclopedia of Chemical Technology 4th edn 877-915 (Wiley, 1995).

2. Molero, H., Bartlett, B. F. \& Tysoe, W. T. The hydrogenation of acetylene catalyzed by palladium: hydrogen pressure dependence. J. Catal. 181, 49-56 (1999).

3. Studt, F. et al. Identification of non-precious metal alloy catalysts for selective hydrogenation of acetylene. Science 320, 1320-1322 (2008).

4. Lewis, J. D. Separation of acetylene from ethylene-bearing gases. US Patent $3,837,144$ (1974).

5. Matsuda, R. et al. Highly controlled acetylene accommodation in a metalorganic microporous material. Nature 436, 238-241 (2005).

6. Furukawa, H., Cordova, K. E., O'Keeffe, M. \& Yaghi, O. M. The chemistry and applications of metal-organic frameworks. Science 341, 1230444 (2013).

7. Sato, H. et al. Self-accelerating CO sorption in a soft nanoporous crystal. Science 343, 167-170 (2014).

8. Zhao, X. et al. Selective anion exchange with nanogated isoreticular positive metal-organic frameworks. Nat. Commun. 4, 2344 (2013)

9. An, J. et al. Metal-adeninate vertices for the construction of an exceptionally porous metal-organic framework. Nat. Commun. 3, 604 (2012). 
10. Xiang, S. et al. Microporous metal-organic framework with potential for carbon dioxide capture at ambient conditions. Nat. Commun. 3, 954 (2012).

11. Li, J.-R. et al. Porous materials with pre-designed single-molecule traps for $\mathrm{CO}_{2}$ selective adsorption. Nat. Commun. 4, 1538 (2013).

12. Vaidhyanathan, R. et al. Direct observation and quantification of $\mathrm{CO}_{2}$ binding within an amine-functionalized nanoporous solid. Science 330, 650-653 (2010).

13. Chen, B., Xiang, S. \& Qian, G. Metal-organic frameworks with functional pores for recognition of small molecules. Acc. Chem. Res. 43, 1115-1124 (2010).

14. Lin, Q., Wu, T., Zheng, S.-T., Bu, X. \& Feng, P. Single-walled polytetrazolate metal-organic channels with high density of open nitrogen-donor sites and gas. J. Am. Chem. Soc. 134, 784-787 (2012).

15. Férey, G. et al. A chromium terephthalate-based solid with unusually large pore volumes and surface area. Science 309, 2040-2042 (2005).

16. Zhao, X. et al. Hysteretic adsorption and desorption of hydrogen by nanoporous metal-organic frameworks. Science 306, 1012-1015 (2004)

17. Farha, O. K. et al. De novo synthesis of a metal-organic framework material featuring ultrahigh surface area and gas storage capacities. Nat. Chem. 2, 944-948 (2010).

18. Mohideen, M. I. H. et al. Protecting group and switchable pore-discriminating adsorption properties of a hydrophilic-hydrophobic metal-organic framework. Nat. Chem. 3, 304-310 (2011).

19. Zhang, Y.-B. et al. Geometry analysis and systematic synthesis of highly porous isoreticular frameworks with a unique topology. Nat. Commun. 3, 642 (2012).

20. Zhang, J.-P. \& Chen, X.-M. Optimized acetylene/carbon dioxide sorption in a dynamic porous crystal. J. Am. Chem. Soc. 131, 5516-5521 (2009).

21. Li, B. et al. Enhanced binding affinity, remarkable selectivity, and high capacity of $\mathrm{CO}_{2}$ by dual functionalization of a rht-type metal-organic framework. Angew. Chem. Int. Ed. 51, 1412-1415 (2012).

22. Burd, S. D. et al. Highly selective carbon dioxide uptake by $\left[\mathrm{Cu}(\mathrm{bpy}-\mathrm{n})_{2}\left(\mathrm{SiF}_{6}\right)\right]$ (bpy-1 =4,4'-bipyridine; bpy-2=1,2-bis(4-pyridyl)ethene). J. Am. Chem. Soc. 134, 3663-3666 (2012).

23. Nugent, P. et al. Porous materials with optimal adsorption thermodynamics and kinetics for $\mathrm{CO}_{2}$ separation. Nature 495, 80-84 (2013).

24. Shekhah, O. et al. Made-to-order metal-organic frameworks for trace carbon dioxide removal and air capture. Nat. Commun. 5, 4228 (2014).

25. Li, B. et al. Metal-cation-directed de novo assembly of a functionalized guest molecule in the nanospace of a metal-organic framework. J. Am. Chem. Soc. 136, 1202-1205 (2014).

26. Ma, L., Mihalcik, D. J. \& Lin, W. Highly porous and robust 4,8-connected metal-organic frameworks for hydrogen storage. J. Am. Chem. Soc. 131, 4610-4612 (2009).

27. Lan, Y. Q., Jiang, H. L., Li, S. L. \& Xu, Q. Mesoporous metal-organic frameworks with size-tunable cages: selective $\mathrm{CO}_{2}$ uptake, encapsulation of $\mathrm{Ln}^{3+}$ cations for luminescence, and column-chromatographic dye separation. Adv. Mater. 23, 5015-5020 (2011).

28. Motkuri, R. K. et al. Fluorocarbon adsorption in hierarchical porous frameworks. Nat. Commun. 5, 4368 (2014).

29. Li, B., Wen, H. M., Zhou, W. \& Chen, B. Porous metal - organic frameworks for gas storage and separation: what, how, and why? J. Phys. Chem. Lett. 5, 3468-3479 (2014).

30. Li, B. et al. A porous metal - organic framework with dynamic pyrimidine groups exhibiting record high methane storage working capacity. J. Am. Chem. Soc. 136, 6207-6210 (2014)

31. Chen, B. et al. A microporous metal-organic framework for gaschromatographic separation of alkanes. Angew Chem. Int. Ed. 45, 1390-1393 (2006).

32. Guo, Z. et al. A metal-organic framework with optimized open metal sites and pore spaces for high methane storage at room temperature. Angew Chem. Int. Ed. 50, 3178-3181 (2011).

33. He, Y., Zhou, W., Krishna, R. \& Chen, B. Microporous metal-organic frameworks for storage and separation of small hydrocarbons. Chem. Commun. 48, 11813-11831 (2012)

34. Farha, O. K. et al. Metal - organic framework materials with ultrahigh surface areas: Is the sky the limit? J. Am. Chem. Soc. 134, 15016-15021 (2012).

35. DeCoste, J. B. et al. Metal-organic frameworks for oxygen storage. Angew. Chem. Int. Ed. 53, 14092-14095 (2014).

36. Xiang, S. et al. Rationally tuned micropores within enantiopure metal-organic frameworks for highly selective separation of acetylene and ethylene. Nat. Commun. 2, 204 (2011)

37. Das, M. Y. et al. Interplay of metalloligand and organic ligand to tune micropores within isostructural mixed-metal organic frameworks (M'MOFs) for their highly selective separation of chiral and achiral small molecules. J. Am. Chem. Soc. 134, 8703-8710 (2012).

38. Bloch, E. D. et al. Hydrocarbon separations in a metal-organic framework with open iron(II) coordination sites. Science 335, 1606-1610 (2012).
39. He, Y., Krishna, R. \& Chen, B. Metal-organic frameworks with potential for energy-efficient adsorptive separation of light hydrocarbons. Energy Environ. Sci. 5, 9107-9120 (2012).

40. Xiang, S., Zhou, W., Gallegos, J. M., Liu, Y. \& Chen, B. Exceptionally high acetylene uptake in a microporous metal-organic framework with open metal sites. J. Am. Chem. Soc. 131, 12415-12419 (2009).

41. Xiang, S. et al. Open metal sites within isostructural metal-organic frameworks for differential recognition of acetylene and extraordinarily high acetylene storage capacity at room temperature. Angew Chem. Int. Ed. 49, 4615-4618 (2010).

42. Yang, S. et al. Supramolecular binding and separation of hydrocarbons within a functionalized porous metal-organic framework. Nat. Chem. 7, 121-129 (2015).

43. Wen, H. M. et al. A microporous metal-organic framework with rare lvt topology for highly selective $\mathrm{C}_{2} \mathrm{H}_{2} / \mathrm{C}_{2} \mathrm{H}_{4}$ separation at room temperature. Chem. Commun. 51, 5610-5613 (2015).

44. Spek, A. L. PLATON, A Multipurpose Crystallographic Tool (Utrecht Univ., 2001).

45. Myers, A. L. \& Prausnitz, J. M. Thermodynamics of mixed gas adsorption. AIChE. J. 11, 121-130 (1965)

46. Breck, D. W. Zeolite Molecular Sieves: Structure, Chemistry and Use (John Wiley and Sons, Inc., 1974).

47. Sircar, S. \& Myers, A. L. Gas Separation by Zeolites. In Handbook of Zeolite Science and Technology. (eds Anesbach, S. M., Carrado, K. A. \& Dutta, P. K.) (Marcel Dekker Inc., 2003).

48. Li, J. R., Kuppler, R. J. \& Zhou, H. C. Selective gas adsorption and separation in metal-organic frameworks. Chem. Soc. Rev. 38, 1477-1504 (2009).

49. Aguado, S., Bergeret, G., Daniel, C. \& Farrusseng, D. Absolute molecular sieve separation of ethylene/ethane mixtures with silver zeolite A. J. Am. Chem. Soc. 134, 14635-14637 (2012).

50. Giannozzi, P. et al. QUANTUM ESPRESSO: A modular and open-source software project for quantum simulations of materials. J. Phys. Condens. Matter 21, 395502 (2009).

51. Smith, M. B. \& March, J. March's Advanced Organic Chemistry 6th edn 363-364 (Wiley, 2007).

52. Voitekhovich, S. V., Vorobév, A. N., Gaponik, P. N. \& Ivashkevich, O. A Synthesis of new functionally substituted 1-R-tetrazoles and their 5-amino derivatives. Chem. Heterocycl. Compd 41, 999-1004 (2005).

53. Krishna, R. \& Long, J. R. Screening metal - organic frameworks by analysis of transient breakthrough of gas mixtures in a fixed bed adsorber. J. Phys. Chem. C 115, 12941-12950 (2011).

54. Krishna, R. The maxwell - stefan description of mixture diffusion in nanoporous crystalline materials. Microporous Mesoporous Mater 185, 30-50 (2014).

55. Krishna, R. Separating mixtures by exploiting molecular packing effects in microporous materials. Phys. Chem. Chem. Phys. 17, 39-59 (2015).

56. Britt, D., Furukawa, H., Wang, B., Glover, T. G. \& Yaghi, O. M. Highly efficient separation of carbon dioxide by a metal-organic framework replete with open metal sites. Proc. Natl Acad. Sci. USA 106, 20637-20640 (2009).

57. Hilden, D. L. \& Stebar, R. F. Evaluation of acetylene as a spark ignition engine fuel. Energy Res. 3, 59-71 (1979).

58. Bhattacharya, S. \& Gubbins, K. E. Fast method for computing pore size distributions of model materials. Langmuir. 22, 7726-7731 (2006).

\section{Acknowledgements}

This work was supported by the Welch Foundation AX-1730 (B.C.) and the NSFC (grant no. 21371102; T.L.H.). Y.H. thanks the support from the KAUST Office of Competitive Research Funds (OCRF, Awards no. URF/1/1672-01-01).

\section{Author contributions}

T.L.H. and B.C. conceived and designed the experiments and co-wrote the paper. T.L.H performed most of the experiments and analysed the data. H.W. and B.L. performed a part of characterization of MOF material. R.K. contributed to the IAST calculations and breakthrough simulations. H.W. and W.Z. worked on all computational investigations. Y.Z., Y.H., XW and W.Z. performed the column breakthrough tests. Z.Y. and S.X assisted the analysis of crystal structure. All authors discussed the results and commented on the manuscript.

\section{Additional information}

Accession codes: The X-ray crystallographic coordinates for structures reported in this Article have been deposited at the Cambridge Crystallographic Data Centre (CCDC), under deposition number CCDC 1044083. These data can be obtained free of charge from The Cambridge Crystallographic Data Centre via www.ccdc.cam.ac.uk/ data_request/cif.

Supplementary Information accompanies this paper at http://www.nature.com/ naturecommunications 
Competing financial interests: The authors declare no competing financial interests.

Reprints and permission information is available online at http://npg.nature.com/ reprintsandpermissions/

How to cite this article: Hu, T.-L. et al. Microporous metal-organic framework with dual functionalities for highly efficient removal of acetylene from ethylene/acetylene mixtures. Nat. Commun. 6:7328 doi: 10.1038/ncomms8328 (2015). (c) (i) This work is licensed under a Creative Commons Attribution 4.0 International License. The images or other third party material in this article are included in the article's Creative Commons license, unless indicated otherwise in the credit line; if the material is not included under the Creative Commons license, users will need to obtain permission from the license holder to reproduce the material. To view a copy of this license, visit http://creativecommons.org/ licenses/by/4.0/ 